\title{
Research on "Difficulty in seeking a doctor" and Scalpers
}

\author{
Sheng Cui \\ Anhui University of Finance and Economics 962 Caoshan Road, Bengbu, Anhui 23300, China
}

Keywords: "Difficulty in seeking a doctor", scalping, medical resources, supervision

\begin{abstract}
When the issue "Difficulty in seeking a doctor" has been increasingly concerned in China, one intractable trouble is the scalpers in medical sector. Based on existing documents and data, by contrastive analysis, this study analyses the relation between "Difficulty in Seeking a doctor" and scalpers, and provides some solutions according to roots of scalpers. By analysis on scalping in medical service, the researcher tries to develop a general method for exploring scalper-related problems.
\end{abstract}

\section{Introduction}

At the beginning of 2017, a doctor, Sun, from People's Hospital of Jiangsu province was retaliated because of accusing scalpers, which caused widespread concern and discussion on the internet. As a matter of fact, the notorious scalpers have been a big trouble in medical sector in China. Scalping of registration, which refer to qualification to accept medical service, brings not only imbalance in the allocation of scarce medical resources and inconvenience for patients to seek a doctor, but also an irrational growth in medical cost. The scalper refers to a person who buys a large number of tickets or coupons by various interest relations and means and resells them at a high price. At present, the relevant reports and academic research mainly have the following viewpoints about the scalpers in medical market.

\section{Literature review}

\subsection{Causes of scalping}

From the perspective of economic theory, most scholars, Yu Zhuanli [2012] and Mou Siyu [2015], believe that the rampage of the scalpers in medical market result from the imbalance between supply and demand. The deviation of price from value gives rise to the formation of scalpers, Shi Guang [2003]. It is also considered the lack of laws and inadequate hospital management as important factors.

\subsection{Views on scalpers}

Most scholars or journalists have different views on the scalpers in the medical market, but not completely negative. Some studies, like Yang Gengshen [2016], suggest that scalpers have aggravated the difficulty in seeking a doctor and that they are making improper profits. However, most studies, including Su Jianyi [2016] and [Courty 2003a], tend to affirm the economic rationality of scalpers' existence and the enlightenment to solve the problem of having difficulty in seeking a doctor.

\subsection{Solutions}

To eliminate negative impact that scalping pose on medical market, to settle scalper problem, Shi Guang [2003] reckoned that present supply need to be improved, and call for a more reasonable pricing on registration fee. And most researcher believe an well-knit registration system should be built. 


\section{Causes of scalping in the medical market}

\subsection{The economic basis for scalping}

It's widely known that the scalpers are quite active in activities that accessed by tickets, which is a perennial trouble for regulation. In China, they even occupied hospitals. The economic essence behind the phenomenon of scalpers is the imbalance between supply and demand. It is also the reflection the serious imbalance in the supply and demand of medical resources.

Hospital Beds (per 1000 people) is an important indicator of the supply of medical resources. The following table shows that China's number of beds per thousand people in 2014 was only 4.85. Compared with other countries with abundant medical resources in the world, Hospital Beds (per 1000 people) in our country is far from sufficient. As of 2015 this data was only 5.11. The supply of existing medical resources cannot meet the requirements of all patients; therefore the scalpers have become a means for patients to seek medical resources.

Table1

\begin{tabular}{|l|c|c|c|c|c|c|c|}
\hline & $\begin{array}{c}\text { High-income } \\
\text { countries }\end{array}$ & $\begin{array}{c}\text { Middle-incom } \\
\text { e countries }\end{array}$ & $\begin{array}{c}\text { The } \\
\text { USA }\end{array}$ & Germany & Australia & Japan & China \\
\hline $\begin{array}{l}\text { Hospital } \\
\text { Beds } \\
\text { (per1000 } \\
\text { people) }\end{array}$ & $\mathbf{9 . 0}$ & $\mathbf{3 . 4}$ & 9.2 & 10.5 & 11.2 & 9.0 & 4.85 \\
\hline
\end{tabular}

Data Sources: World Bank Open Data, China Statistical Yearbook 2015

The behavior of the scalpers' in hospitals involves three economic subjects: scalpers, hospitals and patients. For the purpose of maximizing the benefits, scalpers make use of the loopholes in the current hospital registration system to look for arbitrage space, so that they can meet the needs of patients. In many cases, the needs of patients are a rigid demand, which brings a great benefit space to the traffickers and lets them be engaged in trade registration regardless of risk and punishment.

In economics, the balanced state is the best state for a product in the market, which means that when the price is balanced, the amount of goods that the buyer is willing and able to purchase is exactly equal to the quantity the seller is willing and able to sell. When we assume that the medical resources are commodities, because the supply is less than the equilibrium quantity, the price that the consumer is willing to pay is also higher than the equilibrium price and the price requested by the supplier. It is precisely because of the difference in price that scalpers can gain big profit opportunities. As long as there is sufficient shortage of medical resources, there will be consumers who are willing to pay higher than the normal market price, and then the scalpers will never disappear.

\subsection{Other causes}

Certainly, lack of medical resources is not the only reason for the rampage of scalpers and the difficulty in seeking a doctor. There are other factors.

In "Criminal Law", "Public Security Administration Punishment Law" and so on, there are distinct standards and penalties for the governance of reselling tickets, entrance tickets and other vouchers. However, there are no clear and strict legal requirements for the behavior of trade registration. Low cost for illegal scalping become an important factor for the rampage of scalpers. As a result, the lack of laws leads to the unscrupulous scalpers and the powerless supervision.

In China, the hospitals which are rampant with scalpers are mainly concentrated in the places with high medical levels and complete medical service like Shanghai, Beijing and Guangzhou, which demonstrates the regional imbalance in the development of our country's medical industry. The patients' requirements cannot be resolved locally, so they turn to the hospitals with high medical levels, and then the number of patients increased accordingly, especially in large-scale 
general hospitals. The price margin appears when the demand is more vigorous while the supply cannot be increased in the short term.

In addition, the survivor of scalpers also thanks to the insufficient of technology, mechanism and management in hospitals, patients' high anxiety about their diseases and the ignorance to the rules.

\section{Damages resulted from scalping}

Before discussing the dangers of the scalpers, it is necessary to recognize their "rationality" in economic activity. The consequence of market transaction is that consumers are willing to pay high price from scalpers to reflect the market price of medical service, which implies the current deviation between medical service and the actual market value. Nevertheless, the dangers of the scalpers outweigh their rationalities. This paper will analyze the dangers for the following aspects.

\subsection{The impacts on the patients}

There is no doubt that the existence of the scalpers is a danger to most patients. It takes time, money and physical to get an appointment number with doctors for those patients who observe the rules, while the phenomenon of trade registration through the scalpers breaks the rules and seriously damages the interests of the rule-followers. In light of this, the waiting time for medical treatment has been increased for patients with emergent illness but cannot pay the high registration fee. The worst thing is that those patients will miss the best treatment time due to the long waiting time, then resulting in a loss which can never be made up. Beyond doubt, the existence of the scalpers greatly increases the cost of medical treatment for patients and exacerbates the difficulties in seeking a doctor.

\subsection{The impacts on the medical market}

The negative externalities of the scalpers should not be ignored. They drive the overall registration fee up, and thus indirectly damage the interests of other patients. Generally speaking, the registration fee is directly priced, and will not be affected. However, in certain circumstances, such as the hospital registration fee is very low, the price posted by the scalpers can be widely accepted, which will cause the situation that almost no one would willing to keep normal outpatient registering and charging operation, and then the hospital must make adjustments by raising the registration fee.

Furthermore, the behavior of scalpers wastes numerous hospital resources. The registration that eventually traded is only a tiny part of the number belonging to the scalpers, while other number will only be abandoned because of its expiry. More seriously, the scalpers disrupt the normal order of medical treatment, which makes the current tense physician-patient relationship become more vulnerable.

\section{Suggestions}

\subsection{Increasing the supply of medical resources}

Fundamentally speaking, difficult medical treatment and high medical cost are caused by the tight supply of medical resources. To solve the problem of the scalpers, it is necessary to increase the supply of medical resources. China's investment in medical industry has increased year by year, and the supply of medical resources is also on the rise. Our government needs to continue to invest in public health, strengthen management, ensure investment efficiency, alleviate and solve the problem of inadequate supply of medical resources.

\subsection{Ensuring a balanced allocation of medical resources}

Difficulty in seeking a doctor is not a result of inadequate supply of medical resources. Apart from the uneven allocation of medical resources in various regions and the differences in medical conditions, the unbalanced distribution of hospitals at all levels is also one of the important factors. 
Table2

\begin{tabular}{|c|c|c|c|c|c|c|c|}
\hline & Nationwide & Beijing & Jilin & Yunnan & Qinghai & Hubei & Zhejiang \\
\hline $\begin{array}{l}\text { The number of } \\
\text { medical and } \\
\text { health } \\
\text { institutions per } \\
100 \text { square } \\
\text { kilometers }\end{array}$ & 10.31 & 57.96 & 10.92 & 6.23 & 0.87 & 19.11 & 31.48 \\
\hline $\begin{array}{l}\text { The number of } \\
\text { professional } \\
\text { public health } \\
\text { institutions per } \\
100 \text { square } \\
\text { kilometers }\end{array}$ & 0.320 & 0.671 & 0.232 & 0.288 & 0.025 & 0.302 & 0.464 \\
\hline
\end{tabular}

Data Resource: The Statistical Information Center of National Health and Family Planning Commission of People's Republic of China (2015)

It can be seen from the table that there is a huge gap in the construction of medical and health and an unbalanced distribution of medical resources in each region. The regional difference is also reflected on the distribution of professional public health institutions, the essence of which is the unbalanced allocation of medical resources at different levels. The high-grade hospitals in developed areas are often concentrated with patients and rampant with scalpers. It is recommended that the health sector should pay attention to the balanced allocation of medical resources, while paying attention to the balance of medical resources at different levels, in order to meet the needs of patients and to reduce the situation of some medical institutions concentrated with too many patients.

\subsection{Strengthening management and supervision}

Given the fact that the lack of medical resources cannot be changed in the short term, the management and supervision should be strengthened to regulate market operation. As mentioned above, one of the reasons why scalpers are so rampant is the low legal cost. Medical service is an activity concerned with the people's interest, so the traffickers who disrupt the normal order deserve to be severely punished. The legislature should speed up the pace of legislation, crack down on the speculation of the scalpers, and raise costs of being illegal.

What's more, as a direct provider of medical services, the hospital should strengthen the management of medical procedures. They can take the following measures: designing a reasonable appointment registration and registration system to compress the speculative space that the scalpers can make use of; strengthening the internal supervision in the hospital; completely eradicating the behavior that the hospital staff conspires with the scalpers to conduct the trade registration; severely punishing the staff who violates the rules; regulating the order from the supervisors.

\section{References}

[1] N. Gregory Mankiw. Principles of Microeconomics 7th ed [M]. Worth Publishers. New York, 2010

[2] Courty, Pascal. Some Economics of Ticket Resale [J]. Journal of Economic Perspectives 17(2): 85-97

[3] Melissa Boyle, Lesley Chiou. The Effect of Ticket Resale Laws on Consumption and Production in Performing Arts Markets [J], Eastern Economic Journal. 2012, 38(2): 210-222

[4] Wang Zhiyong, Wang Man. Economic Analysis of "Scalpers" Behaviors [J]. Journal of Beijing Technology and Business University (social science). 2008. 23(4): 21-24 
[5] Ye Dezhu, Hu Beiping, Fairness Preferences and Striking Scalpers, Productivity Research [J]. No.1 2009: 32-33.

[6] Shi Guang, Economic Explanation for Scalping at Registration [J]. Journal of Nanjing Medical University (Natural Sciences), 2003, 13(4): 353-355.

[7] Yu Zhuanli, Economics Essence of Scalpers Social Phenomenon [J]. Economy and Management, 2012, 26(12): 13-17 